\title{
Correction: Introduction of allergenic foods from 3 months of age reduces incidence of food allergy in breastfed infants
}

Dalrymple RA, Makwana N. Introduction of allergenic foods from 3 months of age reduces incidence of food allergy in breastfed infants. Arch Dis Child Educ Pract Ed 2017;102:335.

The structured abstract of this Picket paper was written by Dr Kate C Harvey, affiliated with Birmingham Community Healthcare NHS Foundation Trust, Birmingham, UK. The authors would like to apologise for this omission.

(c) Article author(s) (or their employer(s) unless otherwise stated in the text of the article) 2018. All rights reserved. No commercial use is permitted unless otherwise expressly granted.

Arch Dis Child Educ Pract Ed 2018;53. doi:10.1136/archdischild-2016-311409corr1 